\title{
Estratégia como prática social e teoria da ação comunicativa: possíveis aproximações teóricas
}

\section{Strategy as social practice and theory of communicative action: possible theoretical approaches}

\author{
Elisa Zwick ${ }^{1}$ \\ Isabel Cristina da Silva ${ }^{2}$ \\ Mozar José de Brito ${ }^{3}$
}

\begin{abstract}
Resumo
Este artigo visa a discutir as possíveis aproximações teóricas entre a estratégia como prática social (EPS) e a teoria da ação comunicativa (TAC), instituída por Jürgen Habermas. Almejou-se construir um diálogo analítico, destacando as interfaces que podem ser estabelecidas entre esses construtos. Especificamente, buscou-se: (i) descrever o arcabouço teórico da estratégia como prática social; (ii) discutir os aspectos conceituais da teoria da ação comunicativa; e (iii) apresentar as possíveis aproximações teóricas entre a estratégia como prática social e a teoria da ação comunicativa. Argumenta-se que a TAC tem elementos interessantes a contribuir com a estratégia como prática e que, por esse motivo, é necessário explorar as aproximações teóricas. Desse modo, este artigo contribui singularmente para associar o pensamento habermasiano às perspectivas teóricas da estratégia como prática social, especialmente em seus elementos razão e verdade, entendimento e consenso, que ensejam contribuições substanciais da racionalidade comunicativa para a estratégia como prática social.
\end{abstract}

Palavras-chave: Teoria social. Racionalidade comunicativa. Prática estratégica. Historicidade. Consenso.

\begin{abstract}
This article aims to discuss the possible theoretical approaches between strategy as social practice (SSP) and the theory of communicative action (TCA), established by Jürgen Habermas. We intended to construct an analytical dialogue, highlighting the interfaces that may be established between these constructs. Specifically, we sought to: (i) describe the theoretical framework of strategy as social practice; (ii) discuss the conceptual aspects of the theory of communicative action; and (iii) introduce the possible theoretical approaches between strategy as social practice and the theory of communicative action. It is argued that TCA has interesting elements contributing to strategy as a practice and that, for this reason, there is a need to explore the theoretical approaches. So, this article contributes in a unique way to
\end{abstract}

Artigo submetido em 17 de maio de 2013 e aceito para publicação em 24 de janeiro de 2014.

DOI: http://dx.doi.org/10.1590/1679-39518694

1 Doutoranda em administração pela Universidade Federal de Lavras/UFLA; Professora Assistente II da Universidade Federal de Alfenas/UNIFAL-MG. Endereço: UNIFAL-MG - Universidade Federal de Alfenas, Avenida Celina Ferreira Otoni, 4000, Bairro Padre Vítor, CEP 37048-395, Varginha - MG, Brasil. E-mail: elisa.zwick@unifal-mg.edu.br

2 Doutoranda em administração pela Universidade Federal de Lavras/UFLA; Professora Assistente I da PUC Minas Arcos. Endereço: Rua Antonio Veloso, 218, Eldorado, CEP 35588-000, Arcos - MG, Brasil. E-mail: isabel.admpuc@yahoo.com.br

3 Doutor em Administração pela Universidade de São Paulo/USP; Professor Adjunto IV do PPGA da Universidade Federal de Lavras/UFLA. Endereço: DAE/UFLA, Caixa postal 3034, Campus universitário, CEP 37200.00, Lavras-MG, Brasil. Email: mozarbrito@gmail.com 
associate Habermas' thought with the theoretical perspectives of strategy as social practice, especially concerning their elements reason and truth, understanding and consensus, which give rise to significant contributions of communicative rationality to strategy as social practice.

Keywords: Social theory. Communicative rationality. Strategic practice. Historicity. Consensus.

\section{Introdução}

A discussão acadêmica sobre a estratégia como prática social vem se constituindo em um debate epistemológico bastante interessante para as pesquisas em estudos organizacionais. $\mathrm{O}$ corpus de estudo da estratégia vem avançando consideravelmente em termos de seus conceitos e abordagens essenciais, tanto que uma corrente relativamente nova vem trazendo contribuições aos estudos em estratégia: a chamada corrente da "estratégia como prática social" ou ainda "estratégia como prática". Considera-se que a discussão acerca dessa perspectiva ganhou fôlego e notoriedade na academia a partir de 1996, com a publicação da obra Strategy as practice, de Richard Whittington, responsável por levantar essa discussão ao reivindicara consolidação de uma visão estratégica diferente e menos positivista, visto que seu foco passou a se embasar na perspectiva da prática, também debatida como práxis social.

No Brasil, os estudos voltados ao tema encontram-se em estágio inicial, tendo surgido em 2004, fato que pode explicar uma produção pulverizada e com baixa colaboração entre grupos de pesquisa universitários que se dedicam ao assunto (WALTER, AUGUSTO e FONSECA, 2011).

Cumpre aludir que o maior foco de estudos sobre estratégia tem sido destinado à busca de explicações sobre o seu processo de formação, consubstanciado nas obras de Kenneth Andrews, Alfred Chandler, Igor Ansoff, Michael Porter e Henry Mintzberg, entre outros teóricos clássicos; e que pouca atenção foi dedicada às questões relativas à sua implementação, ou seja, à prática do fazer estratégia. $\mathrm{O}$ fato é que o mainstream da estratégia organizacional permaneceu, por muito tempo, focado em debates que cumprem uma agenda de discussão centrada na racionalidade instrumental ou utilitária, haja vista o direcionamento quase que exclusivo para organizações que se destinam à reprodução da lógica capitalista.

Nessa contenda, é importante destacar que a concepção clássica e ortodoxa da gestão baseada na formulação de estratégias compactua aspectos atinentes ao controle hierárquico, ao planejamento formal e à análise executiva, além de se pautar por receituários, prescrições e diretrizes concorrentes (CLEGG, CARTER e KORNBERGER, 2004; VIZEU e GONÇALVES, 2010), ao passo que o foco na abordagem da implementação estratégica envolve um processo mais sistêmico e integrado (WHITTINGTON, 2004). Ademais, em seu desenvolvimento histórico, a estratégia é um campo voltado para a ação, com foco na construção de ferramentas de gestão e nas forças internas e externas à organização (ORLIKOWSKI, 2010).

Desse modo, percebe-se que a abordagem da estratégia como prática social traz novas reflexões acerca do fazer estratégia, a partir de refinamentos filosóficos e sociológicos oriundos do desenvolvimento da teoria social contemporânea. Isto porque o entendimento da estratégia como prática está atrelado a uma análise sociológica e filosófica da prática. É justamente essa concepção que altera o foco da estratégia que, antes vista de modo estrito como uma ferramenta de gestão, passa a ser revisitada no contexto dos fenômenos mais amplos que a envolvem; ou seja, passa-se a levar em conta o contexto macrossocial.

Pensar a estratégia como prática por seus principais autores, da primeira geração até a segunda, bem como através de autores mais recentes, é um importante exercício de levantamento da historicidade do conceito e das suas perspectivas na atualidade. No Brasil, embora ainda poucos estudos tenham sido empreendidos nesse campo, tem-se destinado atenção ao tema também de modo diferenciado daquele empregado no âmbito empresarial. 
Nesse ínterim, percebe-se a necessidade de trazer - em associação ao pensamento da estratégia como prática- a reflexão de Habermas, um dos maiores autores da teoria social contemporânea, voltando-se especialmente à teoria por ele denominada teoria da ação comunicativa (TAC). Essa teoria, representante do pensamento mais genuíno do autor, apresenta-se como uma preciosa ferramenta, na medida em que contribui para interpretar, analisar e refletir a ação. Assim, este estudo está centrado na seguinte questão de pesquisa: quais as contribuições da teoria da ação comunicativa para a estratégia como prática social?

No intuito de trazer à baila essa discussão, é empreendida uma correlação teórica entre a estratégia como prática social e a teoria da ação comunicativa. Para tanto, fez-se necessário apresentar sucintamente a abordagem teórica que envolve cada conceito isoladamente e, por conseguinte, apresentar as possíveis interfaces, conexões e aproximações. Desse modo, este artigo encontra-se estruturado em quatro conteúdos: (i) a abordagem epistemológica da estratégia como prática social (EPS); (ii) a teoria da ação comunicativa (TAC); (iii) as possíveis aproximações teóricas entre a EPS e a TAC; e (iv) as considerações finais e contribuições do estudo.

\section{A Abordagem Epistemológica da Estratégia como Prática Social}

A estratégia tem se configurado como um campo de estudos relativamente importante, merecendo a atenção de uma gama de teóricos que se concentram em discutir a temática por meio de diferentes abordagens e concepções epistemológicas. Apesar da maioria dos estudos privilegiarem perspectivas funcionalistas, bem como enfoques tradicionais, recentemente tem sido observado um maior número de estudos com perspectivas epistemológicas diferentes. Nesse ínterim, emergem as discussões acerca do "fazer estratégia" a estratégia como prática e seus desdobramentos. Todavia, antes de conceituar a estratégia como prática, é necessário esclarecer que esta é uma abordagem em construção, que vem se configurando como uma proposta de síntese e que busca compreender a articulação da ação do indivíduo e da estrutura no processo de constituição da estratégia (CHIA e RASCHE, 2010; ORLIKOWSKI, 2010; WHITTINGTON, 1996).

A priori, tem-se que a corrente de pensamento da estratégia foi impulsionada por duas grandes gerações de teóricos da prática. Conforme destaca Orlikowski (2010), a primeira geração é composta pelas contribuições de Harold Garfinkel - com a obra Estudos em etnometodologia -, Pierre Bourdieu - com a obra Elementos para uma teoria da prática -, Michel Foucault - com Vigiar e punir -, Michel de Certeau - com A prática da vida cotidiana -, Anthony Giddens - com A construção da sociedade - e Charles Taylor - com Filosofia e ciências humanas. Já a segunda geração envolve as obras de Sherry Ortner com Teoria em antropologia desde os anos sessenta, Debra Pickering, com Prática e pós-humanismo, Andreas Reckwitz, com Para uma teoria da prática social e Theodore Schatzki com $O$ retorno da prática na teoria contemporânea.

Já as influências mais recentes sobre teoria e prática contemporâneas incluem os trabalhos de Bruno Latour, Jean Lave, Yrjö Engeström e Theodore Schatzki, baseados em Martin Heidegger, especialmente em sua obra Ser e tempo, e em Ludwig Wittgenstein, com a obra Investigações Filosóficas, conforme esclarecem Feldman e Orlikowski (2011).

Orlikowski (2010) e Feldman e Orlikowski (2011) analisam que a primeira geração de teóricos da prática se pautou pela ênfase nas ações dos agentes, nas interações e improvisações, focando a análise em como estes produzem/reproduzem as estruturas sociais. A segunda geração de estudiosos da prática buscou avançar no debate quanto aos princípios centrais propostos pelos teóricos da primeira geração, ao mesmo tempo em que buscavam desenvolver novos conceitos e entendimentos. Ambas as gerações foram essenciais para o desenvolvimento dos estudos sobre a prática no campo organizacional.

Contudo, é Whittington (1996) que inicia o debate conceitual da estratégia como prática social, partindo de um direcionamento mais empírico, no qual ele busca compreender mais detalhadamente o que de fato fazem 
os estrategistas. O eixo central de sua obra é enfatizar a necessidade de estudar em profundidade a ação e a interação do indivíduo na organização. Para isso, ele defende que é preciso adentrar na realidade do praticante da estratégia e estudar sua ação, interação, destreza, habilidade e seu desempenho. Seguidores de Whittington, como Paula Jarzabkowski e Gerry Johnson também prestam grandes contribuições a esse campo de estudo.

Para Whittington (1996), a estratégia é uma importante prática social, que exige, na sua compreensão, uma séria análise sociológica e filosófica. Pode ainda ser compreendida como algo que as pessoas fazem ou como uma prática social como qualquer outra, haja vista que é um conceito multidimensional e situacional, voltado para a ação. O teórico descreve "estratégia como prática" como a própria ação do "fazer estratégia", buscando examinar com mais detalhes a vida interna dos processos próprios de estratégia (CHIA e HOLT, 2006; TSOUKAS, 2010).

Conforme assevera Tsoukas (2010), a compreensão de estratégia como prática surge dentro de um movimento maior das teorias sociais contemporâneas (practice turn), descrita por Whittington (2004). Portanto, entender a estratégia em termos práticos permite compreender como é que as ações podem ser consistentes e eficazes, sem que estejam atreladas organizacionalmente à existência de planos estratégicos propositais (TSOUKAS, 2010). Vale dizer que a estratégia é minimamente construída pela consistente organização de ações intencionais. Mintzberg e Waters (1982) insistem que as estratégias podem surgir como consequência de ações humanas espontâneas e não de projetos humanos relativos à intencionalidade, como reforçam Chia e Holt (2006).

Assim, é premente destacar que a perspectiva prática da estratégia implica uma compreensão teoricamente fundamentada na reincidência das interações entre as pessoas, atividades, artefatos e contextos, visto que está particularmente bem posicionada para abordar fenômenos organizacionais dinâmicos e emergentes (CHIA e RASCHE, 2010; ORLIKOWSKI, 2010).

Com relação aos estudos nacionais sobre essa temática, embora estejam avançando para uma investigação mais centrada no social, observa-se que o tema conta com pouca quantidade de publicações, o que pode ser verificado ao se pesquisar a composição "estratégia como prática" no Scientific Periodicals Electronic Library (SPELL) e no Scientific Electronic Library Online (SciELO).

Walter, Augusto e Fonseca (2011) identificaram um total de 349 artigos publicados no mundo sobre esse assunto, dos quais somente 35 são de autoria de pesquisadores brasileiros. Alguns direcionamentos desses estudos nacionais são para: (i) a defesa da abordagem da estratégia como prática (CANHADA e RESE, 2009); (ii) as representações sociais e estratégias e as táticas cotidianas (SILVA, CARRIERI e JUNQUILHO, 2011); (iii) as justaposições entre a estratégia como prática e o processo de estratégia (VALADÃO e SILVA, 2012); (iv) a integração entre as perspectivas institucional e de estratégia como prática (WALTER, AUGUSTO e FONSECA, 2011); e (v) a análise da virada da prática nos estudos sobre estratégia (MACIEL e AUGUSTO, 2013). Esses estudos reconhecem a relevância acadêmica e social do tema e conduzem a uma agenda de pesquisa sobre o assunto, a qual permanece, em grande parte, por ser explorada. No entanto, os principais tópicos de interesse de pesquisadores brasileiros em estratégia como prática situam-se teoricamente a partir das descobertas dos autores internacionais.

A contribuição fundamental dos estudos com foco na prática avança consideravelmente no campo de estudos da estratégia. Até porque, o estudo da prática fornece subsídios para enfatizar a própria prática como um elemento fundamental na produção da realidade social, evidenciando respostas de onde e como acontecem as atividades do "fazer estratégia", quem as realiza e quais as competências necessárias. Nessa linha de pesquisa, de maneira geral, procura-se investigar o que os estrategistas realmente fazem. É especificamente a partir dessa reflexão que se atribui importância significativa à prática.

No plano teórico, o estudo da estratégia como prática exige perspectivas que englobem essa heterogeneidade de processos, atividades, atores e também sua contextualização, imersão e idiossincrasias. No plano 
epistemológico, essa ênfase na estratégia como prática requer uma reflexão da pesquisa científica como ação prática (GRAND, RÜEGG-STÜRM e ARX, 2010).

\section{Novos enfoques teóricos para a estratégia como prática social}

Além das abordagens tradicionais, a estratégia como prática social também tem sido discutida sob a ótica da praxeologia de Pierre Bourdieu, da genealogia do poder de Michel Foucault, da teoria da estruturação de Anthony Giddens, da epistemologia heideggeriana e da abordagem construcionista e socioculturalista, entre outras correntes teóricas. Especificamente a respeito da epistemologia heideggeriana, tem-se que esta contribui com o debate da estratégia como prática por meio do seu direcionamento filosófico prático, consubstanciado no trabalho de Martin Heidegger. Como um dos filósofos mais proeminentes do século XX, uma das obras fundamentais de Heidegger (1989) é Ser e Tempo. Nela, o pensador aborda o sentido do ser, levantando inúmeras questões sobre a tradição da ontologia, na busca por uma explicação das coisas, o que implica, entre outros elementos, o questionamento sobre a formação das ciências. Por isso, a obra passou a ser vista como representativa do pensamento humano universal.

O foco dos estudos desse filósofo é o indivíduo e suas atribuições essenciais como a razão, a mudança, os valores e o conhecimento empírico. Ele propõe uma ontologia interpretativa radicalmente diferente da abordagem convencional (SKÖLDBERG, 1998), buscando compreender não apenas o indivíduo dentro de seu contexto histórico, mas também o que esse contexto diz sobre os que nele vivem e se relacionam.

Assim, a ideia do fazer estratégia leva, em grande medida, à análise das dimensões de Ser e Tempo, de Heidegger (1989). Isso porque o filósofo elabora compreensões do campo mais amplo de práticas sociomateriais, levando em conta as várias intencionalidades e a linguagem como o mecanismo que media a ação. De acordo com essa abordagem, a estratégia deve ser vista como coletividade, pois as atividades humanas são mutuamente constituídas e precisam ser avaliadas na dimensão de seus aspectos espontâneos (TSOUKAS, 2010). Por esse direcionamento, a ontologia interpretativa de Heidegger pode ser utilizada nas pesquisas sobre estratégia como prática, pois a compreensão do Ser orienta os estudos e pesquisas sobre a prática estratégica. Além disso, a partir dessa obra, o pensador insere-se no âmbito da filosofia da linguagem, conferindo-lhe também uma contribuição especial.

Conforme anunciam Chia e Holt (2006), o trabalho de Heidegger articula uma teoria relacional da ação humana que, por sinal, é muito adequada quando se pretende buscar explicações para as ações intencionais e práticas. Especificamente nesse quesito, contribui para explicar o que os estrategistas realmente fazem (que é o ponto crucial das pesquisas de estratégia como prática). Assim, desenvolve-se uma visão de estratégia segundo a qual as práticas cotidianas são a base do fazer estratégia nas organizações, e não apenas aspectos secundários em um processo incremental.

Além do mais, a grande contribuição da filosofia heideggeriana consiste em pensar a estratégia como um elemento mais condizente com a estrutura social e organizacional da atualidade, de modo a compreendê-la como um fenômeno social (TSOUKAS, 2010) e não somente uma técnica analítica para melhorar o sucesso da empresa e fornecer um quadro de análise (CHIA e HOLT, 2006). Entretanto, Sköldberg (1998) assinala que o impacto dos estudos de Heidegger na administração, em especial, nos estudos sobre estratégia, só se deu muito tardiamente, o que pode ter inviabilizado o desenvolvimento ontológico desse campo de investigação.

A pesquisa da estratégia como prática social aglutina, além do pensamento filosófico e das concepções ontológicas da abordagem heideggeriana, as pressuposições da epistemologia construcionista. Conforme Gergen e Joseph (2004), essa abordagem cumpre um importante papel nesse campo de estudos, pois em 
lugar de uma visão monológica, fornece uma visão dialógica que favorece a compreensão da estratégia como uma prática (HOSKING, 2011).

Cumpre aludir que a investigação construcionista possui um caráter emancipatório e expositivo e está centrada, sobretudo, na tentativa de explicação dos processos pelos quais os indivíduos entendem e dão conta do mundo, conforme enfatizam Grand, Ruegg-Sturm e Arx (2010). Na concepção dos referidos autores, essa corrente critica a racionalidade individual e contesta o predomínio das dicotomias inquestionáveis nas ciências sociais (sujeito/objeto), permitindo avanços no nível empírico, teórico e epistemológico da estratégia como prática. Ademais, de acordo com a epistemologia construcionista, a pesquisa em estratégia deve enfatizar a importância fundamental de desvelar e desconstruir conceitos tomados como corretos, de modo a transcender algumas oposições fundamentais e abrir as "caixas-pretas" da estratégia (GERGEN e JOSEPH, 2004; HOSKING, 2011).

Dentre as tantas contribuições teóricas que debatem a estratégia como prática, cabe mencionar a abordagem da teoria da estruturação de Anthony Giddens, também um importante teórico da prática. Para ele, compreender a atividade das pessoas é o objetivo central da análise social. Segundo Whittington (2010), nessa perspectiva, o autor desenvolveu o conceito de estrutura, de agência e de estruturação, que possuem importância intrínseca à pesquisa prática e aos estudos da estratégia como prática.

Ao redigir sobre a dualidade da estrutura, em obra que leva esse nome no português, Giddens (2000) enfatiza que tal dualidade remete ao caráter recursivo da vida social e expressa a dependência entre agência e estrutura, termos que Habermas define como mundo da vida e mundo do sistema. A dualidade é compreendida por Giddens como simultaneidade dos sistemas sociais que são, ao mesmo tempo, meio e resultado das práticas que os constituem. Também fundamentada em outras obras de Giddens, a teoria da estruturação reconstrói uma série de ideias que ultrapassam fronteiras nacionais e disciplinares, ao mesmo tempo em que coloca uma alternativa instigadora: a reconciliação da ação e da coletividade que compõem a vida social organizada. Cohen $(1999$, p. 395) destaca que uma das contribuições mais significativas da teoria da estruturação, que vai além da reconciliação entre ação e coletividade, é o fato desta "desembaraçar a teoria social dos dilemas que são inerentes tanto ao positivismo quanto às teorias da ação social", permitindo entender as inter-relações da estrutura e da ação humana na pesquisa em estratégia como prática.

Ao avançarmos nessa discussão, é premente destacar que um aspecto proeminente da abordagem de Giddens é o fato dele destacar as práticas sociais como procedimentos, métodos ou técnicas hábeis, executadas apropriadamente pelos agentes sociais (COHEN, 1999; JARZABKOWSKI, 2008). Partindo dessa compreensão e estendendo essa prerrogativa aos estudos de estratégia nas organizações, percebe-se que a análise se desloca para tratar de forma mais explícita os processos estratégicos gerais e as atividades daqueles que "fazem estratégia".

Com efeito, a teoria da estruturação oferece para a estratégia como prática social elementos atrativos, como a atenção para o detalhe microssociológico, a sensibilidade ao contexto institucional e a abertura à mudança. A teoria, portanto, pode vir a fundamentar interpretações quanto a efeitos e limitações potenciais de diferentes padrões de gestão, de formulação estratégica da ação ou a elaboração de estratégias institucionais. Nesse diapasão, Whittington (2010) adverte que uma oportunidade para a estratégia, assim como para os pesquisadores da prática, é explorar a teoria da estruturação mais completamente, a fim de compreender as estruturas sociais mais amplas, ou instituições, em que a estratégia ocorre, bem como o processo que envolve sua concepção.

Juntamente com Giddens e Certeau, também Pierre Bourdieu se classifica como um dos principais teóricos da prática. Ele trata a prática como atividade humana que representa a vida social (GOMEZ, 2010). Por esse motivo, a praxeologia bourdieusiana contribui para a corrente de estudos da estratégia como prática. Segundo Splitter e Seidl (2011), o trabalho de Bourdieu reafirma a importância das relações entre os agentes e o campo, bem como as disposições para a ação, chamando a atenção para uma visão sistêmica da prática. 
Cumpre atentar que a contribuição da praxeologia bourdieusiana para a estratégia como prática envolve discutir os elementos, conceitos e idiossincrasias do campo (mundos sociais e campos de forças), do capital (elementos que definem as posições dos agentes no campo) e do habitus (ordem social do campo), como forma de compreender melhor a prática (EVERETT, 2002; GOMEZ, 2010; SPLITTER e SEIDL, 2011).

Splitter e Seidl (2011) acrescentam que a praxeologia bourdieusiana permite superar algumas dicotomias da teoria organizacional que influenciam o campo da estratégia, como os dualismos acerca do ambiente micro e macrossocial, entre a estrutura e a agência, bem como entre a escolha racional e a escolha emergente. Portanto, mobilizar o sistema completo de prática no campo e incorporar o habitus e o capital permite conceber a estratégia como perspectiva prática, pelo entrelaçamento do indivíduo e do contexto social, que são entendidos como codependentes (EVERETT, 2002; GOMEZ, 2010). Ademais, ao envolver-se com a objetivação participante e praticar a reflexividade proposta por Bourdieu, os pesquisadores podem captar a lógica da práxis estratégica e, dessa maneira, desvendar as possibilidades e os limites dentro dos quais as práticas de estratégia são promulgadas.

Assim como a teoria de Pierre Bourdieu, os escritos de Michel Foucault também fornecem contribuições para a estratégia como prática. Tais contribuições estão relacionadas com a discussão sobre a formação dos saberes e dos discursos de verdade nas relações de poder. Foucault estudou o poder disciplinar em Vigiar e punir e Microfísica do poder, bem como estudou o biopoder e os dispositivos da loucura e da sexualidade em História da sexualidade. Para isto, em lugar de uma análise histórica, realiza uma genealogia ou um estudo histórico que não busca uma origem única e causal, mas que se baseia no estudo das multiplicidades e das lutas. Além disso, ele abriu novos campos no estudo da história e da epistemologia (DIXON, 2007). O referido autor informa que na concepção foucaultiana as relações de poder não são somente relações negativas, uma vez que apresentam um viés de possibilidades positivas para o seu exercício, haja vista que o poder representa um elemento disciplinador e ao mesmo tempo promovedor do saber. Ele não somente reprime, mas também produz efeitos de verdade e saber, constituindo verdades, práticas e subjetividades (ALLARD-POESI, 2010; CHAN, 2000; DIXON, 2007).

Nessa discussão, Chan (2000, p.13) salienta que a abordagem genealógica de Foucault é emulada para conduzir uma reflexão crítica da estratégia como prática, questionando limites da subjetivação ou da forma de subjetividade que sujeitos livres têm tomado como "uma parte autoconsciente na aquisição, aprendizagem e modificação das competências específicas do sujeito". Allard-Poesi (2010) acrescenta que o poder, como definido por Foucault, é utilizado para justificar o porquê dos agentes agirem de forma diferente do "planejado" no processo estratégico, com liberdade para questionar a relação de poder e tomar decisões conforme seus interesses e os de sua organização.

Outra corrente de pensamento que também ajuda a compreender as especificidades da estratégia como prática é a vertente socioculturalista. Para Chia e Mackay (2007), essa corrente surge como forma de explicar e compreender a ação, tendo como recurso estruturas simbólicas de significado. Reckwitz (2002) advoga que nessa abordagem o enfoque não está na estratégia em si, mas nos padrões corporais e nas falas dos estrategistas. Trata-se, pois, de uma abordagem teórica baseada na observação, que ajuda a compreender melhor o comportamento dos estrategistas por meio de suas ações nas estruturas.

Estudar os movimentos corporais significa investigar como o corpo manifesta o conjunto de conhecimento que cerca as estratégias práticas. Todavia, a estratégia como prática não é apenas composta pelo desempenho de rotinas corporais, mas inclui o conhecimento das rotinas baseadas nos esquemas de conhecimento compartilhado. Tais esquemas são denominados de códigos por Foucault, habitus por Bourdieu e de molduras por Goffman (CHIA e MACKAY, 2007; RECKWITZ, 2002).

Nesse sentido, o efeito geral das teorias socioculturalistas é trazer à tona a esfera do simbólico e do cognitivo para a abordagem da estratégia como prática, assim como as demais correntes teóricas aqui elencadas trazem fundamentos essenciais a essa abordagem teórica. Apesar de receber contribuições de diferentes naturezas, a estratégia como prática constitui um campo em construção, carecendo de abordagens mais aprofundadas. 
Assim, busca-se discutir essa vertente à luz dos pressupostos da teoria da ação comunicativa de Jürgen Habermas, no intuito de vislumbrar novos avanços para esse corpus de estudo.

\section{A Teoria da Ação Comunicativa: um Mergulho na Concepção Habermasiana}

A teoria da ação comunicativa (TAC) surgiu na comunidade acadêmica filosófica em 1981, como uma das mais significativas correntes filosóficas da contemporaneidade. Como obra fundamental do pensamento de Habermas, teórico da segunda geração de pensadores da escola de Frankfurt, ela é resultado dos seus esforços para reconstruir uma teoria da sociedade com intenção prática.

No entanto, essa teoria não se resume às exposições feitas por ele sobre esse tema somente em Teoria do agir comunicativo (HABERMAS, 2012a; 2012b), mas já vinha sendo desenvolvida em obras anteriores, como Conhecimento e interesse (1980), Teoria y praxis (1987) e Técnica e ciência como ideologia (1994). Essa observação se faz necessária para que não haja confusão entre o título de uma obra e a definição conceitual da teoria geral desenvolvida por Habermas, que encontra seu momento crucial na obra Teoria do agir comunicativo.

Na TAC, considerada uma nova teoria da sociedade, Habermas não apenas valoriza aquilo que de autores como Marx, Weber, Durkheim, Mead, Freud, Piaget e Parsons considera vivo e atual, como também ao dialogar com tais ideias, busca aclarar e superar suas debilidades. Como afirma McCarthy (1987, p. 446), Habermas pensa "con ellos para ir más allá de ellos". Isso se torna suficiente para demonstrar o caráter vasto e a complexidade técnica engendrada pela teoria habermasiana, que envolve uma ampla análise sociológica. Andrews (2011), por sua vez, analisa que o fato de a maioria dos autores com quem Habermas dialoga serem enquadrados na tradição sociológica clássica ocorre por ele considerar que o ramo da sociologia se mostra mais propenso a conectar seus conceitos básicos à problemática da racionalidade.

Como já dito, a TAC, fundamentada desde os trabalhos anteriores do filósofo, busca refundar a teoria da sociedade num novo nível, no contexto de um novo paradigma para a reconstrução da teoria crítica da sociedade com intenções práticas. Esse novo paradigma consistiu na resposta de Habermas à crise da consciência e da razão, pela afirmação de um paradigma fundado na linguagem, mas não na linguagem sintático-semântica, e sim na linguagem da fala. É nessa teoria que Habermas desenvolve o marco categorial e as bases normativas de sua teoria social na forma de uma teoria geral da ação comunicativa.

Sob a lente de Reese-Schäfer (2009), a ideia central do agir comunicativo, a teoria habermasiana segundo a qual se pode avaliar todas as sociedades, é a de que:

é possível atribuir as patologias da Modernidade, sem nenhuma exceção, à invasão da racionalidade econômica e burocrática em esferas do mundo da vida, às quais essas formas de racionalidade não são adequadas e, por isso, levam a perdas de liberdade e de sentido. $\mathrm{O}$ agir comunicativo é concebido por Habermas de modo a abrir as oportunidades para um entendimento em sentido abrangente, não restritivo. (REESE-SCHÄFER, 2009, p. 46)

Entrementes, pode-se afirmar que um dos fundamentos principais dessa teoria, como diz Siebeneichler (2003), está no fato de que a competência específica da espécie humana de poder falar uma linguagem é condição necessária e suficiente para que os homens atinjam a maioridade intelectual e o objetivo de Habermas, que está na racionalidade. Ao envolver a comunicação, a teoria está diretamente relacionada à compreensão, que é possível quando os seres humanos são iguais em alguns aspectos. Pela compreensão é presumível estabelecer uma ligação entre dois pontos, uma vez que a comunicação acontece quando as pessoas têm algo em comum para compartilhar. A própria tradução de comunicar significa "tornar comum, 
transmitir algo, estabelecer uma ligação entre dois pontos; e isso pressupõe algo que possa ser partilhado tanto por quem fala quanto por quem ouve" (XARÃO, 2011, p. 78).

A TAC, segundo Habermas (2012b), está ordenada seguindo três propósitos relacionados entre si: (i) desenvolver um conceito de racionalidade que não esteja preso nem limitado pelas premissas subjetivistas e individualistas da filosofia e da teoria social moderna; (ii) construir um conceito de sociedade, em dois níveis, que integre os paradigmas do "sistema" e do "mundo da vida"; e (iii) buscar, sobre esse pano de fundo, uma teoria crítica da modernidade que a analise e reconheça suas patologias, de tal maneira que contribua mais para sua retificação do que para o abandono do projeto da ilustração. Esse propósito pretende ultrapassar a colonização do mundo da vida pelo sistema, em que se tem, por exemplo, o direito positivo e o debate técnico das questões normativas.

Por outro lado, Habermas (2012a) considera quem age comunicativamente portador de três pretensões racionais de validade: (i) a verdade, baseada no agir teleológico (orientado para uma finalidadefrequentemente, interpretado como utilitarista ou instrumental) e que tem referência no mundo objetivo; (ii) a correção, calcada no agir normativo e referenciada no mundo objetivo; e (iii) a veracidade, cuja pretensão de validade é sinônimo de autenticidade, embasada no tipo de agir dramatúrgico (de qualidades, de certo modo "parasitárias"), tendo como referência o mundo subjetivo- embora, seja possível um julgamento objetivo. O agir comunicativo seria o somatório desses três conceitos de ação, cuja pretensão de validade é o entendimento, havendo uma referência reflexiva a todos os três mundos. Para Reese-Schäfer (2009), as três pretensões de validade pressupõem que qualquer parceiro do diálogo age comunicativamente; ou seja, não se pode presumir de antemão sua irracionalidade.

Assim, o desenvolvimento do modelo comunicativo está voltado para a interpretação de como a esfera pública está constituída, além de significar que Habermas aloca uma concepção dual de sociedade em que, por um lado, está o sistema e, por outro, o mundo da vida- conceito nascido na filosofia da consciência. Segundo Kelly (2004), na elaboração do conceito de sistema, Habermas reteve um componente weberiano na sua teoria social, uma vez que caracteriza o sistema como uma esfera de interação humana, centrada em torno de mecanismos de direção não comunicativa. Assim, a esfera do sistema é definida pelo filósofo como um elo instrumental existente em uma esfera de interação social. Essa esfera, que pode ser a economia ou o estado administrativo, compõe-se, portanto, de agentes que reagem instrumentalmente.

Contrabalançando com o sistema está a esfera do mundo da vida. Habermas (2012b) define o mundo da vida como um conceito acessório do agir comunicativo, que está relacionado com definições comuns da situação. Entre outros aspectos, o mundo da vida está relacionado ao conceito durkheimiano de "consciência coletiva" e a conceitos do cotidiano que apenas narram fatos e relações sociais. $\mathrm{O}$ mundo da vida, segundo analisa Kelly (2004, p. 42) é, portanto, "a esfera de interação centrada na cultura, na sociedade e na personalidade que está estruturada comunicativamente e reproduzida através do argumento e dos atos de expressão comunicativa".

Assim, o mundo da vida é a esfera que permite a expressão de diferentes dimensões da racionalidade prática, sendo importante que permaneça independente dos efeitos niveladores dos sistemas sociais. Quando isso não acontece, exaure-se a proteção efetiva entre o mundo da vida e o sistema, passando o mundo da vida a ser colonizado. A colonização do mundo da vida, segundo exemplificado por Kelly (2004, p. 42), ocorre quando "a mídia controla subsistemas da economia e o Estado intervém com recursos e burocracia, significando a reprodução simbólica do mundo da vida". Isso corrobora o pensamento do filósofo de que é preciso que haja a compreensão das situações por parte dos indivíduos.

Além disso, Freitag (1990, p. 112) assinala que "as peças-chave da TAC são a concepção dialógica (comunicativa) da razão e o caráter processual da verdade". Na TAC, razão e verdade deixam de ser valores absolutos universais para serem definidos formalmente como procedimentos, como regras do jogo fixadas consensualmente. Razão e verdade resultam da interação do indivíduo com o mundo dos objetos, das pessoas e da vida interior. Por isso, a razão e a verdade só podem decorrer da organização social dos atores, 
interagindo em situações dialógicas. Isso significa que a razão não tem sua sede no sujeito epistêmico, como pensava Kant, mas sim na intersubjetividade da ação comunicativa da fala. Por outro lado, o conceito de razão só faz sentido como razão dialógica, ou seja, como resultante daquilo que, em um contexto social, vivido e compartilhado por autores linguisticamente competentes, pode ser elaborado como aceito por todos.

Nesse ínterim, Habermas se dedica às condições e possibilidades da atividade social comunicativa, em que o entendimento é um conceito central e complexo, utilizado por ele para explicitar a racionalidade e o agir comunicativo (SIEBENEICHLER, 2003), sendo empregado em dois sentidos principais: (i) como compreensão dos significados dos atos de fala; e (ii) como produção do entendimento, isto é, a realização do conteúdo entre os participantes da comunicação acerca dos fatos, objetivos, avaliações, normas sociais e experiências vivenciais subjetivas. Siebeneichler (2003, p. 94) analisa que o entendimento em Habermas caracteriza o próprio processo comunicativo voltado para o consenso, que pressupõe "troca ativa e pacífica de opinião e de informações entre participantes de uma determinada práxis social".

Cumpre aludir que o consenso comunicativo não pode ser confundido com a ideia ingênua de qualquer consenso, pois é um consenso que pressupõe regras entre os sujeitos comunicativos, que são a própria condição para o consenso do agir comunicativo. Caso se tratasse de qualquer consenso, que não precisa respeitar nenhum pressuposto moral ou contextual, jamais ele serviria para fundamentar uma teoria da verdade. Pesqueux e Vasconcelos (2013) concordam com tal inclinação habermasiana ao analisar o pensamento do filósofo sobre a filosofia moral, cuja função seria "depreender a ética subjacente a cada forma de comunicação", sem caber aos filósofos a determinação dos termos absolutos pelos quais se decide adotar um comportamento em uma determinada situação.

$\mathrm{Na}$ análise de Habermas (2012b, p. 221), o consenso tem a ver com o "reconhecimento intersubjetivo da pretensão de validade que o falante une a uma exteriorização". Para ele, um modo de comunicação e uma pretensão de validade "se relacionam num contexto de "referências mútuas intactas". Com isso, Habermas vai supor que há uma situação em que não existe nenhum elemento de coação, a não ser a pujança do melhor argumento. É o que ele chama de situação ideal de fala. Essa situação pode ser tomada como critério da argumentação discursiva, porque implica uma distribuição sistemática de chances de escolha e de realização dos atos de fala:

[...] Chamo ideal a uma situação de fala em que as comunicações não somente não vêm impedidas por influxos externos contingentes, nem tampouco pelas coações que se seguem da própria estrutura da comunicação. A situação ideal de fala exclui as distorções sistemáticas da comunicação [...]. As situações ideais de fala têm que cumprir, primeiro, duas condições triviais: 1) todos os participantes potenciais em um discurso têm que ter a mesma oportunidade de empregar atos de fala comunicativos, de sorte que em todo momento tenham a oportunidade tanto de abrir um discurso como de perpetuá-lo mediante intervenções e réplicas, perguntas e respostas; 2) todos os participantes no discurso têm que ter igual oportunidade de fazer interpretações, afirmações, recomendações, dar explicações e justificações e de problematizar, julgar ou refutar as pretensões de validade delas, de sorte que no fim das contas nenhum preconceito permaneça isento da tematização e da crítica. (HABERMAS, 2001, p. 153)

Essas são as condições que garantem que os participantes da comunicação estejam convencidos da possibilidade de chegar a um entendimento, porque todos supõem, em qualquer situação de interação, que eventuais mal-entendidos surgidos durante a comunicação podem ser resolvidos por meio da discussão que se instaura num discurso.

Esse é, em síntese, o processo consensual da verdade em Habermas, baseado num conceito de razão mais amplo, não mais na relação sujeito-objeto, e sim numa relação entre sujeitos comunicativos em que, pela linguagem, a competência do discurso se repõe como a retomada do uso emancipatório da razão. Visto dessa 
forma, "o consenso habermasiano não é um projeto teleológico, a fim de ser alcançado pela sociedade no futuro; trata-se de um pressuposto filosófico necessário para situar sua teoria no campo da racionalidade comunicativa" (ANDREWS, 2011, p. 15).

Nesse sentido, a TAC de Habermas, como operacionalizadora de caminhos para a emancipação, é vista como uma possibilidade objetiva, nos moldes de uma consciência antecipadora, como indica Bloch (2005). A TAC permite desenvolver a capacidade de organização das pessoas em termos práticos, de modo que possam superar a colonização do mundo da vida pelo sistema. Isto porque, ao estar embasada no agir comunicativo, a TAC é distinta do agir estratégico, pelo fato de que todos os participantes "perseguem fins ilocucionários para alcançar um comum acordo que sirva de fundamento a uma coordenação consensual dos planos de ação a serem almejados por cada indivíduo" (HABERMAS, 2012a, p. 512).

\section{Possíveis Aproximações Teóricas Entre a Estratégia como Prática Social e a Teoria da Ação Comunicativa}

Ao cunhar um novo paradigma para a reconstrução da teoria crítica da sociedade com intenções práticas, a TAC presta grandes contribuições aos estudos filosóficos da prática, podendo, consequentemente, ser caracterizada como influenciadora da corrente da estratégia como prática social. O ímpeto de focar a consciência da razão através da fala (produção discursiva da linguagem) orienta a compreensão da estratégia como uma prática organizacional, permitindo novas interpretações para o "fazer estratégia".

Nesse sentido, quando inicialmente se relacionam as contribuições da ontologia interpretativa de Heidegger com as elaborações da estratégia como prática social, percebe-se uma tênue relação que sua teoria pode engendrar com a TAC habermasiana e, por conseguinte, aproximar esta da estratégia como prática. Embora não tenha dado nenhuma contribuição à política, Heidegger compreende a estratégia a partir de uma perspectiva coletiva, versando sobre a linguagem como mecanismo mediador da ação, para o que a teoria da ação comunicativa adiciona ricos elementos.

O consequente desenvolvimento de Habermas (2003) em sua TAC leva o filósofo a pensara respeito da política deliberativa, que passa a ser um critério potencializador da emancipação, bem como uma forma elevada de relacionamento das instâncias do sistema com o mundo da vida. Nesse pensar a politicidade, ele vai, portanto, além da visão heideggeriana. Embora Habermas (2012a; 2012b) tenha apontado a necessidade de se estabelecer uma racionalidade comunicativa nos lugares de fala, isto é dificultado pela desproporcionalidade de comunicação entre o mundo da vida e o sistema - este em que se localiza a esfera do Estado. Isto é, os lugares de fala são estabelecidos pelos espaços políticos que os atores sociais ocupam, e quando os mesmos estão situados no mundo do sistema, esses sujeitos podem estar em um lugar desfavorável quando comparados àqueles que ocupam espaços de fala no mundo da vida. Anunciar sua fala de um lugar que esteja situado no mundo da vida seria o momento em que os sujeitos podem adotar a estratégia como prática social. Por isso, para Habermas (2003), caberia à sociedade, ou seja, ao mundo da vida, o papel de figurar como protagonista no sistema político, para lhe dar direcionamentos mais consensuais.

A contribuição habermasiana para pensar o sistema (político) vem contribuir para a estratégia como prática social no momento em que se pensa toda a prática social como também imbuída de intenções políticas. Nesse sentido é que a comunicação (entendida como linguagem, consciência discursiva) é o elo para que as ações sejam concretizadas. Como uma teoria que lida com a força da ação, a estratégia como prática social necessita ser conectada também à prática comunicativa, que está isenta de coerção, segundo definiu Habermas (2001).

Esse entendimento do filósofo não se aplica apenas à teoria social, mas também ao campo da administração, especialmente, quando seu debate ocorre a partir de constructos não positivistas. A TAC contribui para a 
construção do entendimento, por meio do uso da linguagem, envolta em conceitos e valores comuns, para que as pessoas se situem dentro de uma determinada estratégia que para elas seja a mais apropriada. Cabe lembrar que a adoção de uma estratégia se torna adequada em um contexto, o que tem a ver com o ambiente social e histórico. Tal aspecto vem ao encontro da epistemologia construcionista, quando a mesma procura explicar os processos no mundo em que os sujeitos coabitam, não tomando uma ou outra estratégia como $a$ correta, mas considerando, sobretudo, o contexto em que se elabora uma estratégia como determinante do pensamento para se chegar a ela, o que depende, essencialmente, do elemento consensual entre as partes.

Por outro lado, ao se tomar por base elementos da teoria da estruturação de Giddens (2000) para pensar a estratégia como prática social, o mesmo elemento da historicidade, também caro à TAC está assinalado: "na teoria da estruturação, os tipos de recursos aos quais os agentes têm acesso e as habilidades cognoscíveis envolvidas nas práticas [...] assim como o seu conhecimento discursivo de condições sociais mais amplas, sempre existem no interior de limites históricos e espaciais determinados" (COHEN, 1999, p. 416). Essa ideia é melhor fundamentada pelo próprio autor:

[...] De acordo com a noção de dualidade da estrutura, as regras e os recursos são mobilizados pelos actores através da produção de interaç̧ões [...] [e] são reconstituídos através de tais interacções. (...). Trata-se de uma relação distinta da que subjaz à relação das "partes" com os "todos" na coordenação dos actores e grupos [...]. Tal significa afirmar que as diferenças que constituem os sistemas sociais reflectem uma dialética de presenças e ausências no espaço e no tempo. (GIDDENS, 2000, p. 45-46)

Fica também evidente a atenção de ambos os autores ao desenvolvimento social e às questões que o mesmo reverbera. À advertência de Whittington (2010) sobre explorar a teoria giddeniana para compreender estruturas sociais mais amplas é possível aliar os elementos da TAC, tendo em vista que Habermas (2012a; 2012b) também alocou uma concepção dual de sociedade. Operacionalizá-la é possível especialmente quando a teoria habermasiana pensa em formas de integração paradigmática, realizadas em seus três conceitos de ação, que levam ao entendimento através da reflexividade e dão valor à racionalidade prática, desenvolvida de modo circular na sociedade.

Já os discursos de verdade nas relações de poder pautadas por Foucault fazem pensar que, ao unirem-se à perspectiva foucaultiana os elementos da TAC, pode haver uma contribuição para positivar as relações - as mesmas apontadas por Habermas como desproporcionais. Uma vez que enxerga o poder como dominação que se manifesta nos microprocessos da interação humana com as instituições, Foucault (1987) permite pensar a questão da liberdade e da resistência como os dois mais importantes princípios da teoria organizacional pós-moderna como reflexividade e mudança (CHAN, 2000). Habermas (2012a; 2012b) contribui nesse viés quando levanta os critérios para o estabelecimento da razão e da verdade, que fazem sentido mediante a ação comunicativa e a razão dialógica, respectivamente - para alcançar o que é razoável a todos.

Nesse sentido, a TAC contribui, mais uma vez, para o debate da estratégia como prática social quando permite, pela dialogicidade, o alcance da melhor estratégia no conjunto social. Para alcançá-la, vale, igualmente, o respeito aos pressupostos socioculturalistas, quanto à observância dos padrões culturais, bem como as falas dos estrategistas. Uma vez que Habermas (2012a) referencia o mundo da vida como espaço da construção comunicativa da consciência coletiva, a práxis social, para ele, está baseada no entendimento. Essa é uma importante contribuição para a elaboração da estratégia como prática, pois é nesse ponto que se pode configurar a adoção de critérios democráticos no processo da elaboração estratégica.

Além do mais, o agir comunicativo concebido por Habermas abre caminhos para uma compreensão mais abrangente e aprofundada da prática estratégica e dela como prática social, no sentido de proporcionar elementos para esclarecer algumas questões-chave: (i) o que os estrategistas realmente fazem? (ii) como eles pensam as estratégias e como as praticam? (iii) quais os condicionantes do processo estratégico? 
Dentre outros tantos questionamentos, infere-se ainda que o foco no processo dialógico da linguagem na produção do consenso habermasiano tende a suscitar reflexões mais críticas nesse campo de investigação. Ao suscitar tais reflexões, a estratégia como prática avança de uma perspectiva prescritiva da prática (concepção ortodoxa) para uma compreensão sociológica e filosófica da prática, que pressupõe uma relação horizontalizada entre sujeito e objeto do conhecimento, remetendo aos elementos desdobrados pela teoria crítica.

Tem-se que a razão e a verdade na teoria da ação comunicativa deixam de representar valores absolutos universais para serem definidas formalmente como procedimentos e como regras do jogo fixadas consensualmente. Essa orientação, de certo modo, tende a desconstruir as "verdades e razões" da estratégia como plano de ação da organização, abrindo espaço para um debate menos instrumental e mais reflexivo e dialógico. Portanto, a TAC, ao desenvolver um conceito de racionalidade que não se prende às premissas subjetivistas e individualistas da teoria social moderna, ultrapassa a colonização do mundo da vida, ou seja, o debate técnico das questões normativas. Nesse sentido, essa teoria norteia a estratégia como prática social a transcender as orientações pragmáticas e normativas do processo estratégico, rumo a uma compreensão mais substantiva e subjetiva da práxis.

Ademais, a TAC de Habermas pode operacionalizar possibilidades objetivas que, pensadas nos moldes de Guerreiro Ramos (2009) a partir de Weber, apontam alguns caminhos à emancipação. Conceitualmente, segundo Freund (1987, p. 58), "a possibilidade objetiva constrói um 'quadro imaginário', uma utopia [...], faz abstração, pelo pensamento, de um ou vários elementos da realidade, para indagar o que teria podido acontecer no caso considerado", questionando as estruturas pré-determinadas. Essa visão, engendrada por Guerreiro Ramos (2009), leva a pensar em caminhos para a emancipação no momento em que o autor qualifica a teoria $P$ - teoria das possibilidades - como a que permite questionar os campos existentes e construir outros, numa busca pela atualização de possíveis novos sistemas sociais. É somente por meio da consciência crítica, que recusa qualquer tipo de dominação ou autoritarismo, dando-se pela ação dialógica, que se desmistificam conhecimentos antes assimilados a priori. É esse nível de consciência, qualificada como crítica, que Paulo Freire (2001) defende que possa ser alcançado apenas pelo processo educativo centrado na realidade dos indivíduos, ou seja, por meio de uma pedagogia crítica do indivíduo e da sociedade.

Destarte, o agir comunicativo do estrategista envolve processos interacionais em que todos os participantes da estratégia harmonizam entre si seus planos individuais de ação para um plano coletivo. Portanto, é numa lógica de aprendizagem contínua que a coordenação pela linguagem passa a representar uma forma de ação que tem grandes implicações na compreensão da estratégia como uma prática social. Orientando-se pela concepção habermasiana, o agir do estrategista é conduzido pela fala, do mesmo modo que a fala orienta a ação. Tal compreensão permite migrar de uma razão instrumental para uma razão comunicativa, avançando com relação aos dualismos positivistas que limitam avanços na concepção da estratégia como prática social.

\section{Considerações Finais}

Como mãe de todas as ciências, historicamente, a filosofia tem norteado a construção do pensamento e contribuído para o desdobramento das ramificações da árvore do conhecimento. Diante da temática tratada neste artigo, verifica-se a sua presença no debate de questões voltadas às ciências sociais aplicadas, em que pensadores importantes colaboram efetivamente para o engajamento filosófico e ontológico nas mais diferentes temáticas sociais. O exercício de trazer os pensadores da filosofia que contribuem para o debate da estratégia como prática social é fundamental para pensar no rumo desses estudos, para que não se fixem como meros modismos, mas englobem questões diferenciadas ou mesmo perspectivas estratégicas que estejam em constante interlocução. Além disso, pensar a estratégia como um aspecto também microssocial é fundamental. 
Refletir acerca da estratégia como prática social representa o abandono do positivismo arraigado e a aceitação de novos paradigmas de pesquisa para o avanço do campo da estratégia. Ademais, a premissa da estratégia como uma importante prática social já demonstra avanços em termos de conhecimento desse campo de estudos, e tal concepção exige uma séria análise sociológica, capaz de transformar esse conhecimento em uma maneira de melhorar o modo como são pensadas e conduzidas as estratégias na sociedade como um todo. Também é preciso atentar para o fato de que, para compreender a estratégia como prática, os pesquisadores dessa vertente defendem que se deve escapar de uma construção linear de pensamento.

Em suma, as pesquisas sobre estratégia como prática precisam estar sustentadas em uma epistemologia que reconheça as várias formas pelas quais as práticas estratégias são desenvolvidas, bem como os vários modos de intencionalidade e linguagem que, fundamentalmente, sustentam como fazer a estratégia. Portanto, as concepções aqui elencadas, ao combinar múltiplas dimensões de análise, sugerem elementos para cobrir uma importante lacuna no campo dos estudos da "estratégia como prática", pois enfatizam tanto a ação das pessoas e sua práxis em interações estratégicas, quanto a ação da organização, unindo, horizontalmente, conteúdo e processo, além de integrar, verticalmente, abordagens macro e micro da ação, da estrutura e da relação entre ambas.

Nesse sentido, chega-se ao entendimento de que a perspectiva da estratégia como prática ainda não propôs um modelo teórico totalmente estruturado e único. Trata-se, pois, de um paradigma em construção, que se associa a outros paradigmas, como o habermasiano, mas que requer maiores estudos e novos direcionamentos teóricos e práticos.

Diante do exposto, acredita-se que a pesquisa da estratégia como prática pode reorientar o ensino da estratégia, uma vez que busca contextualizar o conhecimento teórico-empírico por meio da análise da prática estratégica e não só da dimensão processual. Não obstante, observa-se a complexidade e a abrangência desse campo de estudos e o quão premente é a necessidade de maiores pesquisas com aprofundamentos tanto teóricos quanto empíricos, vislumbrando levantar discussões e premissas que tragam novos esclarecimentos científicos.

Acima de tudo, é fundamental compreender a estratégia como prática social enquanto produto do contexto, sendo ele institucionalizado ou não. Nesse meio, o poder da linguagem é fundamental para interpretar o mundo, em que precisa haver uma constante abertura para a mudança. $\mathrm{O}$ passo seguinte à pesquisa da estratégia como prática é o empreendimento de ações efetivas que possam apontar caminhos às questões práticas e aos problemas do mundo da vida. Nesse sentido, a TAC pode contribuir para o desenvolvimento de uma visão que leve à adequação das estruturas vigentes às necessidades, o que se dá pelo emprego da racionalidade comunicativa, cuja dialogicidade permite transcender a racionalidade limitada, ou ainda, a racionalidade instrumental ou utilitarista.

Destarte, tendo em vista que os estudos centrados na prática adentram o campo dos estudos da estratégia, é recomendável, para haver um avanço nessa área, que se tenham como norte os critérios dispostos pela TAC como elementos que possam acrescentar avanços fundamentais à convivência, especialmente, quando se atenta para a diferenciação entre mundo da vida e mundo do sistema.

O espaço em que os atores da estratégia como prática agem é o do mundo do sistema, organizando consciente e intencionalmente suas ações. Essas ações, quando pautadas pela racionalidade comunicativa habermasiana, estão envoltas no consenso que, pela dialogicidade preconiza a todos os indivíduos uma situação ideal de fala, o que é de grande valia à teoria habermasiana (HABERMAS, 2012a; 2012b). Manter viva essa perspectiva pode vir a desencadear constantes avanços no desenvolvimento de estratégias que levem mais em conta o mundo da vida ou a consciência coletiva. Porém, é contínua a necessidade de equalizar os lugares de onde falam os atores sociais. 


\section{Referências}

ALLARD-POESI, F. A Foucauldian perspective on strategic practice: strategy as the art of (un)folding. In: GOLSORKHI, D. (Ed.). The Cambridge handbook on strategy as practice. Cambridge, UK: Cambridge University Press, 2010. p. 168-184.

ANDREWS, C. W. Emancipação e legitimidade: uma introdução à obra de Jürgen Habermas. São Paulo: Ed. Unifesp, 2011.

BLOCH. E. O princípio esperança, Rio de Janeiro: Ed Uerj; Contraponto, 2005.v. 1.

CANHADA, D. I. D.; RESE, N. Contribuições da "estratégia como prática" ao pensamento em estratégia. RebraeRevista Brasileira de Estratégia, Curitiba, v. 2, n. 3, p. 273-289, set./dez. 2009.

CHAN, A. Redirecting critique in postmodern organization studies: the perspective of Foucault. Organization Studies, v. 21 , n. 6 , p. 1059-1075, Nov. 2000.

CHIA, R.; HOLT, R. Strategy as practical coping: a heideggerian perspective. Organization Studies, v. 27, n. 5, p. 635-655, May 2006.

; MACKAY, B. Pos-processual challenges for the emerging strategy-as-practice perspective: discovering strategy in the logic of practice. Human Relations, v. 60, n. 1, p. 217-242, Feb. 2007.

; RASCHE, A. Epistemological alternatives for researching strategy as practice: building and dwelling worldviews. In: GOLSORKHI, D. (Ed.). The Cambridge handbook on strategy as practice. Cambridge, UK: Cambridge University Press, 2010. 34-47 p.

CLEGG, S.; CARTER, C.; KORNBERGER, M. A “máquina estratégica": fundamentos epistemológicos e desenvolvimentos em curso. RAE-Eletrônica, v. 44, n. 4, p. 21-31, out/dez. 2004. Disponível em: http://rae.fgv.br/sites/rae.fgv.br/files/artigos/10.1590_S0034-75902004000400004.pdf. Acesso em 07 jun. 2013

COHEN, Ira. J. Teoria da estruturação e práxis social. In: GIDDENS, A.; TURNER, J. (Org.). Teoria social hoje. São Paulo: Ed. Unesp, 1999. 393-446 p.

DIXON, M. A. Transforming power: expanding the inheritance of Michel Foucault in organizational studies. Management Communication Quarterly, v. 20, n. 3, p. 283-296, Fev. 2007.

EVERETT, J. Organizational research and the praxeology of Pierre Bourdieu. Organizational Research Methods, v. 5, n. 1, p. 56-80, Jan. 2002.

FELDMAN. M. S.; ORLIKOWSKI, W. J. Theorizing practice and practicing theory. Organization Science, v. 22, n. 5, p. 1240-1253, Sept./Oct. 2011

FOUCAULT, M. Vigiar e punir: nascimento da prisão. Petrópolis: Vozes, 1987.

FREIRE, P. Ação cultural para a liberdade e outros escritos. 9. ed. Rio de Janeiro: Paz e Terra, 2001.

FREITAG, B. A teoria crítica ontem e hoje. 3. ed. São Paulo: Brasiliense, 1990.

FREUND, J. Sociologia de Max Weber. 4. ed. Rio de Janeiro: Forense Universitária, 1987. 
GERGEN, K. J.; JOSEPH, T. Organization science as social construction: postmodern potentials. The Journal of Applied Behavioral Science, v. 40, n. 2, p. 228-249, June 2004.

GIDDENS, A. Dualidade da estrutura: agência e estrutura. São Bernardo do Campo: Celta, 2000.

GOMEZ, M-L. A bourdieusian perspective on strategizing. In: GOLSORKHI, D. (Ed.). The Cambridge handbook on strategy as practice. Cambridge, UK: Cambridge University Press, 2010. 141-153 p.

GRAND, S.; RÜEGG-STÜRM, J.; ARX, W. V. Constructivist epistemologies in strategy as practice research. In: GOLSORKHI, D. (Ed.). The Cambridge handbook on strategy as practice. Cambridge, UK: Cambridge University Press, 2010. p. 63-78.

GUERREIRO RAMOS, A. A modernização em nova perspectiva: em busca do modelo da possibilidade. In: HEIDEMANN, F. G.; SALM, J. F. (Org.). Políticas públicas e desenvolvimento: bases epistemológicas e modelos de análise. Brasília: Ed. UnB, 2009.

HABERMAS, J. Conhecimento e interesse. In: BENJAMIN, W. et al. Textos escolhidos. São Paulo: Abril Cultural, 1980. 301-312 p. (Os Pensadores).

Teoria y praxis. Madri: Tecnos, 1987.

Técnica e ciência como ideologia. Lisboa: Edições 70, 1994.

Teoría de la acción comunicativa: complementos y estudios prévios. Madrid: Cátedra, 2001.

Direito e democracia: entre facticidade e validade. 2. ed. Rio de Janeiro: Tempo Brasileiro, 2003. v. 2. 2012a. v. 1.

Teoria do agir comunicativo: racionalidade da ação e racionalização social. São Paulo: Martins Fontes, . Teoria do agir comunicativo: sobre a crítica da razão funcionalista. São Paulo: Martins Fontes, 2012b. v. 2.

HEIDEGGER, M. Ser e tempo. 3. ed. Petrópolis: Vozes, 1989.

HOSKING, D. M. Telling tales of relations: appreciating relational constructionism. Organization Studies, v. 32, n. 1, p. 47-65, Jan. 2011.

JARZABKOWSKI, P. Shaping strategy as a structuration process. Academy of Management Journal, v. 51, n. 4, p. 621-650, Aug. 2008.

KELLY, T. Unlocking the iron cage: public administration in the deliberative democratic theory of Jürgen Habermas. Administration \& Society, v. 36, n. 1, p. 38-61, Mar. 2004.

MACIEL, C. O.; AUGUSTO, P. O. M. A “practice turn” e o movimento social da estratégia como prática: está completa essa virada? Revista de Administração Mackenzie, v. 14, n. 2, p. 155-178, Mar./Abr. 2013.

McCARTHY, T. La teoria crítica de Jürgen Habermas. Madrid: Tecnos, 1987.

MINTZBERG, H.; WATERS, J. Tracking strategy in an entrepreneurial firm. Academy of Management Journal, v. 25, n. 3, p. 465-499, Sept. 1982. 
ORLIKOWSKI, W. J. Engaging practice in research: phenomenon, perspective, and philosophy. In: GOLSORKHI, D. (Ed.). The Cambridge handbook on strategy as practice. Cambridge, UK: Cambridge University Press, 2010. 23-33 p.

PESQUEUX Y.; VASCONCELOS, I. F. F. G. Teoria da ação comunicativa e responsabilidade social empresarial: uma proposta de pesquisa. Cad. EBAPE.BR, Rio de Janeiro, v. 11, n. 1, p. 30-40, Mar. 2013. Disponível em: http://bibliotecadigital.fgv.br/ojs/index.php/cadernosebape/article/viewFile/7863/6526. Acesso em 15 jul. 2013.

RECKWITZ, A. Toward a theory of social practices: a development in culturalist theorizing. European Journal of Social Theory. London: Sage Publications, 2002. 243-263 P.

REESE-SCHÄFER, W. Compreender Habermas. 2. ed. Petrópolis: Vozes, 2009.

SIEBENEICHLER, F. B. Jürgen Habermas: razão comunicativa e emancipação. Rio de Janeiro: Tempo Brasileiro, 2003.

SILVA, A. R. L.; CARRIERI, A. P.; JUNQUILHO, G. S. A estratégia como prática social nas organizações: articulações entre representações sociais, estratégias e táticas cotidianas. Rausp - Revista de Administração da USP, v. 46, n. 2, p. 122-134, Abr./Jun. 2011.

SKÖLDBERG, K. Heidegger and organization: notes toward a new research programme. Seand J. Management, v. 14, n. 1/2, p.77-102, 1998.

SPLITTER, V.; SEIDL, D. Does practice-based research on strategy lead to practically relevant knowledge? Implications of a bourdieusian perspective. The Journal of Applied Behavioral Science, v. 47, n. 1, p. 98-120, Mar. 2011.

TSOUKAS, H. Practice, strategy making and intentionality: a heideggerian onto-epistemology for strategy as practice. In: GOLSORKHI, D. et al. (Ed.) The Cambridge handbook on strategy as practice. Cambridge, UK: Cambridge University Press, 2010. 47-61 P.

VALADÃO, J. A. D.; SILVA, S. S. S. Justaposições da estratégia como prática e processo de estratégia: antes da visão pós-processual da estratégia. Revista de Administração Mackenzie, v. 13, n. 2, p. 171-195, Mar./Abr. 2012.

VIZEU, F.; GONÇALVES, S. A. Pensamento estratégico. São Paulo: Atlas, 2010.

WALTER, S. A; AUGUSTO, P. O.; FONSECA, V. S. O campo organizacional e a adoção de práticas estratégicas: revisitando o modelo de Whittington. Cad. EBAPE.BR, v. 9, n. 2, p. 282-298, jun. 2011. Disponível em: http://bibliotecadigital.fgv.br/ojs/index.php/cadernosebape/article/viewFile/5204/3938. Acesso em 07 jun. 2013.

WHITTINGTON, R. Strategy as practice. Long Range Planning, v. 29, n. 5, p. 731-735, 1996.

Estratégia após o modernismo: recuperando a prática. RAE Eletrônica, v. 44, n. 4, p. 44-53, Out./Dez. 2004. Disponível em: http://rae.fgv.br/sites/rae.fgv.br/files/artigos/10.1590_S0034-75902004000400006.pdf. Acesso em 07 jun. 2013.

Giddens, structuration and strategy as practice. In: GOLSORKHI, D. (Ed.). The Cambridge handbook on strategy as practice. Cambridge, UK: Cambridge University Press, 2010. 109-127 p.

XARÃO, F. L. A intolerância é intolerável: notações para um projeto de educação em direitos humanos. In: VIOLA, S. E. A.; ALBUQUERQUE, M. Z. Fundamentos para educação em direitos humanos. São Leopoldo: Sinodal/EST, 2011.77-87 p. 